health will work side by side. The mutual understanding and co-operation thus fostered should prove of great value in their professional careers.

\section{Agricultural Development at Kongwa, Tanganyika}

THE Overseas Food Corporation has announced that, to obtain further advice on the long-term and short-term agricultural policy to be pursued at Kongwa, Tanganyika, the Corporation has appointed a working party, on which the following have con. sented to serve: Mr. G. F. Clay, agricultural adviser to the Secretary of State for the Colonies; Prof. S. H. Frankel, professor of colonial and economic affairs at Nuffield College, Oxford ; Dr. H. H. Storey, deputy director of the East African Agricultural Research Organisation; Mr. A. M. B. Hutt, member for development, Tanganyika Government; Mr. J. C. Muir, member for agriculture, Tanganyika Government. Prof. J. F. V. Phillips, agricultural adviser to the Corporation, will also be a member of the committee, and Sir Charles Lockhart, a member of the board of the Corporation, will be chairman.

\section{History of Science as an Educational Discipline}

A JoINT meeting of the British Society for the History of Science, Science Masters' Association, Association of Women Science Teachers, British Broadcasting Corporation, National Institute of Adult Education and the Workers' Educational Association was held on February 27 at the Royal Institution, London, the subject being "The History of Science in Education". Prof. Herbert Dingle, a vice-president of the British Society for the History of Science, 'was in the chair and, in opening the discussion, pointed out that what guided the pioneers in making fresh advances was rarely what appeared later to be the logical requirements of the situation, but frequently the impacts of other considerations now forgotten. $\mathrm{He}$ directed attention to the courses in history and philosophy of science in the University of London, leading to postgraduate degrees, and commented that many teachers attend these courses. Dr. H. F. Boulind thought that the history of science should form in schools a part of the subject of history, so that the facts of history, including science, may be correlated into one whole. He was of the opinion that in the teaching of science the historical method could impart valuable lessons so that science would not be confused with dogma, and the nature of scientific truth would be appreciated. Mr. K. C. Barnes, while agreeing that the history of science might possibly best be written by a historian who knows science, pointed out that the number of such men is exceedingly few. He thought that there is great lack of interest in science among history students, and examination papers often encourage an extremely narrow view of history, implying no recognition of the part science has played in shaping the modern world; undue specialization in sixth forms at school is to be deplored.

Finally, Mr. F. R. Elwell gave a summary to the meeting of the work done by the British Broadcasting Corporation in science broadcasts to Secondary Modern Schools for children in the age group 11-15. The Corporation has a pamphlet on the history of science in the series of broadcasts to schools. Such broadcasts include biographical studies on great men of science, showing them against the background of contemporary characters, events of general historic interest and the social life of the time. Mr. Elwell thought that the inter-relationship of various aspects of life and culture could be brought out in these talks, and commented that in the field of adult education there are many problems, one being a limited range of vocabulary not adequately realized by many speakers and writers on scientific topics.

\section{Valve Voltmeter for the Laboratory}

A NEW type of valve voltmeter, designed for laboratory use and having an exceptional stability and a high standard of accuracy, has been produced recently by Messrs. Electronic Instruments, Ltd., Richmond, Surrey. This voltmeter is a mainsoperated instrument designed to measure direct- and alternating-current voltages from 0.2 to 250 volts at frequencies from $25 \mathrm{c}$. $/ \mathrm{s}$. to $200 \mathrm{Mc}$. $/ \mathrm{s}$. The makers claim that the accuracy complies with British Standard Specification 89 (1937) for first-grade moving-coil meters. In order to achieve this accuracy, the instrument incorporates a precision moving-coil micro-ammeter with a six-inch finely divided mirror. scale and a knife-edge pointer. There are six voltageranges for both D.C. and A.C. measurements, and, while a 'set zero' control is included, this seldom requires adjustment in practical use. For D.c. mersurements, the input resistance is 50 megohms; for A.c. measurements, there is no resistive path, the input impedance being 5 megohms in parallel with a capacity of 30 or $6 \mathrm{pF}$., depending on whether or not the probe, provided with the instrument, is in use. On A.C the instrument is calibrated in root. mean-square voltages, but it is essentially a peak voltmeter. Resistances from $500 \mathrm{ohms}$ to 500 megohms in four overlapping ranges can also be measured with the low test potential of one volt.

\section{Spiders of the West Indies}

Two recent papers by Miss Elizabeth Bryant direct attention to the state of our knowledge of the spiders of the West Indies. In the first paper (Bull. Mus. Comp. Zoo., Harvard, 100, No. 4; 1948) Miss Bryant deals with the Museum's collection of spiders from Hispaniola, describes 224 species, of which 110 are new, and establishes sixteen new genera. The second (ibid., 103, No, $3 ;$ 1950) deals with the Salticidæ of Jamaica and includes the collection made by Dr. G. W. and Mrs. E. G. Peckham fifty years ago. Twenty-six species in sixteen genera, six of which are new, are described. These papers, which are the result of Miss Bryant's continuing interest in the island fauna of the Caribbean, emphasize the great opportunities which await collectors in this area.

\section{University of Sheffield}

D. K. RoBerts and B. Wilcock have been appointed lecturers in mechanical engineering in the University of Sheffield. The Museum of the Department of Zoology is to be called the Alfred Denny Museum in memory of the first professor of zoology, who laid the foundations for the Museum as it now stands; Prof. Denny was professor of biology in Firth College, University College, Sheffield, and in the University during 1884-1908, and professor of zoology during 1908-25.

\section{Royal Aeronautical Society: Officers}

Tre following have been appointed officers for 1950-51 of the Royal Aeronautical Society: President, Major G. P. Bulman ; Past Presidents, Sir John S. Buchanan, Dr. H. Roxbee Cox and Sir Frederick Handley Page; Vice-Presidents, S. Camm, G. R. 